Article

\title{
The Potential of Volunteered Geographic Information (VGI) in Future Transport Systems
}

\author{
Maria Attard ${ }^{1, *}$, Muki Haklay ${ }^{2}$ and Cristina Capineri ${ }^{3}$ \\ ${ }^{1}$ Institute for Climate Change and Sustainable Development, University of Malta, MSD2080 Msida, Malta; \\ E-Mail: maria.attard@um.edu.mt \\ 2 Department of Civil, Environmental and Geomatic Engineering, University College London, London, WC1E 6BT, UK; \\ E-Mail:m.haklay@ucl.ac.uk \\ ${ }^{3}$ Department of Social, Political and Cognitive Sciences, University of Siena, 53100 Siena, Italy; \\ E-Mail: cristina.capineri@unisi.it \\ * Corresponding author
}

Submitted: 3 March 2016 | Accepted: 3 June 2016 | Published: 16 November 2016

\begin{abstract}
As transport systems are pushed to the limits in many cities, governments have tried to resolve problems of traffic and congestion by increasing capacity. Miller (2013) contends the need to identify new capabilities (instead of capacity) of the transport infrastructure in order to increase efficiency without extending the physical infrastructure. Kenyon and Lyons (2003) identified integrated traveller information as a facilitator for better transport decisions. Today, with further developments in the use of geographic information systems (GIS) and a greater disposition by the public to provide volunteered geographic information (VGI), the potential of information is not only integrated across modes but also user-generated, real-time and available on smartphones anywhere. This geographic information plays today an important role in sectors such as politics, businesses and entertainment, and presumably this would extend to transport in revealing people's preferences for mobility and therefore be useful for decision-making. The widespread availability of networks and smartphones offer new opportunities supported by apps and crowdsourcing through social media such as the successful traffic and navigation app Waze, car sharing programmes such as Zipcar, and ride sharing systems such as Uber. This study aims to develop insights into the potential of governments to use voluntary (crowdsourced) geographic information effectively to achieve sustainable mobility. A review of the literature and existing technology informs this article. Further research into this area is identified and presented at the end of the paper.
\end{abstract}

\section{Keywords}

government; sustainable mobility; transport; VGI

\section{Issue}

This article is part of the issue "Paradigm Shifts in Urban Planning", edited by Matthias Drilling (University of Applied Sciences and the Arts Northwestern Switzerland, Switzerland), Efrat Eizenberg (Israel Institute of Technology, Israel), Janet Stanley (University of Melbourne, Australia), Lee Boon Thong (Nilai University, Malaysia) and Andreas Wesener (Lincoln University Canterbury, New Zealand).

(C) 2016 by the authors; licensee Cogitatio (Lisbon, Portugal). This article is licensed under a Creative Commons Attribution 4.0 International License (CC BY).

\section{Introduction}

The capacity of the transport system to support the growing mobility needs of populations have been pushed to the limit in many cities and the approach of govern- ments to resolve the problem has been to increase capacity (where this is possible) and repeat what has been the practice so far (Banister, 2007). This however has resulted in congested networks, unhealthy living conditions due to air and noise pollution, and infrastructures 
that are both unequal in dealing with particular groups within the population as well as costly to build and maintain. Miller (2013) contends the need to identify new capabilities (instead of capacity) of the transport infrastructure in order to increase efficiency and increase capacity without extending the existing infrastructure. This could easily extend to quality of service where the potential of information to improve a service is high (Brescia Mobilita, 2015).

Susan Kenyon and Glen Lyons (2003)-extending earlier work by Lyons (2001)-described the potential of information to influence travel choices. Specifically they identified integrated traveller information to help make transport decisions. Both the transport industry and the research community supported this thesis with many cities developing multimodal information systems to support sustainability-oriented decisions (Kramers, 2014). A decade later and further developments in the use of geographic information systems (GIS) and a greater disposition by the public to provide volunteered geographic information (VGI), the potential of information is not only to be integrated across different modes but also to be user generated, real time and available on smartphones anywhere. User generated 'geographic' information play today an important role in sectors such as politics, businesses and entertainment, and presumably this phenomena would extend to transport in revealing people's preferences for mobility (Gal-Tzur et al., 2014) and therefore be useful for decision making and support.

The widespread availability of smartphone technology and the growing coverage of ubiquitous data communication networks in urban areas are causing a dramatic transformation in the way geographic information is produced and consumed (Manovich, 2009). It has also offered new opportunities for what are termed cooperative transport systems supported by smartphone apps and crowdsourcing through social media such as the successful community based traffic and navigation app Waze, bought by Google for $\$ 1.3$ billion (Rushe, 2013); Moovit for transit planning; community car sharing programmes such as Zipcar; and more recently peer-to-peer vehicle and ride sharing systems such as Getaround, Uber and Bridj. Some of these systems have already been branded by Lanzendorf (2014) as Mobility 2.0 however many would not be so successful without enough users actively participating and generating information (knowledge co-production). Preliminary analyses of the use of social media in urban transport (using facebook, Twitter and WhatsApp) show good levels of engagement amongst city dwellers (Gruppo Brescia Mobilita, 2014). Other examples include UbiGreen, a mobile tool using (volunteered) geographic information about personal travel to support behaviour change towards greater use of green transport (Froehlich et al., 2009).

It is this revolution in the potential of data-driven planning, management and use of transport systems that has led Winter, Sester, Wolfson and Geers (2011) to call for a new interdisciplinary field called computational transportation science, defined as a science concerned with the study of transport systems where people interact with information systems (e.g. interfaces for driver assistance, or integrated transport information); where systems monitor and interpret traffic (e.g., mining for activity patterns, or crowdsourcing to monitor events); or where systems manage the traffic (e.g. control of traffic flow at traffic lights, or toll management). It is the second objective that is of particular interest to our research here. In particular, the study aims to develop insights into the potential and role of governments to use voluntary (crowdsourced) geographic information and social media effectively for sharing information, creating opportunities for collaboration, enhancing government responsiveness, planning and governance to achieve sustainable mobility and climate change goals (related studies included Bertot, Jaeger, \& Hansen, 2012 and Panagiotopoulos, Bigdeli, \& Sams, 2014).

This article reflects on (i) the technologies that are changing the way travellers move, particularly those using information that is co-produced through crowdsourcing and VGI techniques (ii) the technology potential for supporting and achieving sustainable mobility goals, and (iii) what role exists for governments (if any at all) in the use of user generated geographic information and the new mobility services.

A review of the literature and existing technology informs this article and the objective is to stimulate further research into these growing technologies as well as increasing participation and government role through the development of VGI and Citizen Science for travel and transport. This introduction is followed by a review of literature on the challenges facing cities and urban areas with respect to mobility and the potential of information to modify, support and improve travel behaviour. Section 3 deals with a broad review of new mobility services, providing a typology based on the type of information is used and disseminated. Section 4 defines the potential of the technology, information and behaviour change for sustainable mobility, whilst also discussing the opportunity provided by applying responsible research and innovation to mobility services. Section 5 discusses the role and responsibilities of governments in using information and crowdsourcing for sustainable mobility. The paper also attempts to define the role and need for regulation in this highly dynamic and evolving sector. Finally, Section 6 provides some conclusions and ideas for further research.

\section{Transport and the City}

In September 2015 McKinsey \& Company published an article titled "Urban mobility at a tipping point" in which they claim that new business models and technologies are emerging to solve the mobility challenge faced by cities (Bouton, Knupfer, Mihov, \& Swartz, 2015). Previous to that in 2008, The Economist published an article with the title "Nomads at last", claiming a change in people's 
lives and mobility with the advent of mobile technologies (The Economist, 2008). Dal Fiore, Mokhtarian, Salomon and Singer (2014) provide a set of perspectives on the impact of mobile technologies on travel, but whilst they primarily look at travel behaviour issues, there is an increasing realisation that mobility is changing because of the ubiquitous nature of mobile phones and their advanced functionality and capabilities.

As cities grow across the world the need for effective transport infrastructures is increasingly becoming a major challenge. Existing infrastructure cannot support increasing numbers of vehicles, congestion is costing too much (see Christidis \& Ibanez Rivas, 2012) and the European Environment Agency attributed 432,000 premature deaths across Europe originating from long-term exposure to $\mathrm{PM}_{2.5}, 75,000$ premature deaths linked to $\mathrm{NO}_{2}$ long-term exposure and 17,000 premature deaths associated with $\mathrm{O}_{3}$ short-term exposure (European Environment Agency, 2015). Transport contributes significantly to these pollutants.

The quality of life of millions of people around the world is being affected by transport systems unable to cope with the growing and changing mobility needs. And whilst some cities are experiencing a decline in car ownership (for peak car effects see Metz, 2015), there are others which continue to grow their fleet with even bigger impacts on their economies, environment and public health (see for example Rhode and Muller (2015) mapping air pollution concentrations in China).

\subsection{The Challenges of Transport in Cities}

Sustainable mobility was defined in the European Commission's Thematic Strategy for the Urban Environment as being "a transport system which allows the basic access and development needs of individuals, companies and societies to be met safely and in a manner consistent with human and ecosystem health, and promotes equity within and between successive generations; is affordable, operated fairly and efficiently, offers choice of transport mode, and supports a competitive economy, as well as balanced regional development; limits emissions and waste within the planet's ability to absorb them, uses renewable resources at or below their rates of generation, and, uses non-renewable resources at or below the rates of development of renewable substitutes while minimising the impact on the use of land and the generation of noise" (European Commission, 2004). Over the years this definition has raised many questions. As a vision or aspiration however it has stimulated a change in the thinking of policy makers and stakeholders. Goals like environmental protection and ideas like participatory democracy, which were foreign to the minds of transport planners not so long ago, are now establishing themselves on the transport policy agenda. Despite this, there is still a need for some guiding principles, if 'sustainability' is to become more than green rhetoric (Attard, 2006).
The European Union target for the transport sector is to reduce emissions of greenhouse gases by at least $60 \%$ by 2050 compared with 1990 . There are also targets to move towards means of travel that use less energy, make efficient use of land and pollute less (EU, 2011). There is also support for this through the Clean Air Package and Climate Change obligations which following Paris COP21 look at even stricter measures to reduce $\mathrm{CO}_{2}$ emissions. Governments therefore have an obligation to tackle transport. This obligation could be translated into various roles governments can take to seek the most effective measures to achieve sustainable mobility.

Apart from pollution which has a significant impact on urban dwellers' quality of life, there are other challenges facing transport in cities. More complex mobility patterns supported by hypermobility (Adams, 2001) and what is termed the 'mobile revolution' (Steinbock, 2005) are happening and changes are evolving very fast. Traditional transport planning does not take into consideration these complex, dynamic patterns of movement. Whilst policy and governance have not managed to utilise the potential of this revolution for cities through crowdsourced information, social media, participatory sensing and what is envisaged to be part of smart cities as defined by Batty et al. (2012).

Cities transport systems are changing as a reaction to growing needs. A number of technologies are driving changes in the more traditional modes such as innovative solutions for the future bus (Musso \& Corazza, 2015), electrification, connectivity, and autonomous vehicles (Fagnant \& Kockelman, 2015). Bicycle sharing schemes have increased to over 721 cities worldwide (Meddin \& DeMaio, 2014) and walking is being incentivised through apps such as BitWalking where people generate digital currency whilst walking. Public transport is being challenged by new mobilities offering more demand responsive services and, through technology, alternatives which for some are considered 'disruptive'. This is however highly contested with the example of Uber maybe causing disruption to licensed taxi drivers but certainly not inventing a radical new service, and therefore disrupting very little of the current system.

The future urban transport will be technologically driven, will require private and public financing and as already seen, new business models and ventures to support the mix of modes and services on offer. Technologies and urban populations which are increasingly becoming connected and accustomed to sharing information will offer new opportunities to discover new ways of travel, but is there an opportunity for government to capitalise on this information and use it for policy making?

\subsection{The Potential of Geographic Information and Crowdsourcing}

Over the years as technology progressed a number of authors have tackled the issue of information provision and the opportunities that these offer. Information as a 
facilitator of public transport use is probably the most common purpose, however Lyons and Harman (2002) identified also the potential of comparative information, promoting public transport as a sustainable and viable alternative.

This was supported much later by Kramers (2014) who stated that there is potential in traveler information systems to support sustainability-oriented decisions. She examined nine information systems available at the time and compared their functionality but also the potential of influencing the traveller and direct them to a sustainable alternative. Even more she hinted at the opportunity of community based apps which could support such systems to provide more information. Crowdsourcing is seen here as the 'other' data that could complement public authorities own data. Nash (2010) reviewed the potential of Web 2.0 applications for public participation in transport planning and looked at a number of applications for which data is generated through crowdsourcing, for example www.livablestreets.info. Similarly, Iveroth and Bengtsson (2014) looked at IT as an enabler and identified actors and their social activities as the factors that determine the success of behaviour change. The extent to which people are able and willing to change are key to sustainable mobility policy.

Lyons and Harman (2002) identify a number of issues related to users and information. These include a list of traveller concerns, information packaging and opportunities by which information can influence travel behaviour (see Figure 1). Some of these concerns can be alleviated through crowdsourced information and sharing (e.g. peer-to-peer reviews) and has been to a certain extent tested by apps such as Waze, in the case of car based travel and Moovit for public transport travel. Weiser, Scheider, Bucher, Kiefer and Raubal (2016) have explored how geographic information and communication technology can contribute to support individuals engage in more sustainable lifestyles without posing unrealistic restrictions on their mobility needs (contribution to sustainable mobility). They claim that technology enables novel, interactive, participatory, and collaborative approaches to support people through real-time, user and location-specific feedback on current as well as future behavior. They identify two ways in which locationaware ICT can be utilized for direct support in mobile decision-making and for evaluating the various aspects of people's mobile behavior. The facility offered by technology to users to monitor their travel behavior (for examples see the "Meili Mobility Collector" by Prelipcean, Gidofalvi, \& Susilo, 2014), describe and rate their own mobility performance and peers tagging each other's mobility behavior with 'likes' or emojis, allow for the creation and collection of potentially useful volunteered geographic information.

So far however Government led initiatives have been few and far between. Haklay et al. (2014) drew up a report for the World Bank on Crowdsourced Geographic Information Use in Government and analysed 29 case studies from across the world, out of which only three applications related to transport (the UK's FixMyStreet, Street Bump in Boston and the Portland Transportation Planner). It is evident that despite the potential there has been very little use of such volunteered geographic information by governments for transport planning and policy.

In recent years, development of Web 2.0, of mobile technologies and the possibilities enabled by ubiquitous WiFi has led to information being used to develop a number of new services in the fields of personalised transport (car sharing and taxi hailing services) and public transport (shared on demand transport services). These relatively new services benefit from information being generated primarily through crowdsourced geographic data, and supported by more traditional information about travel habits and activities. Whilst in many cases apps collect information from the service users (e.g. Bridj), in the case of Finland, the Ministry of Transport and Communications rolled out Traffic Lab, a real time traffic information services development in partnership between local government and businesses to collect anonymous traffic data from private vehicles (opting in to the system). Information is collected about traffic through a mixture of in-car systems, GPS, short range radio signals and mobile network (Haaramo, 2014).

1. People undertaking journeys rarely seek information, as journeys are undertaken regularly without much reflection on behaviour beyond habit.

2. People have very poor judgement of cost and time when travelling by car with control over their journeys being seen as important. Public transport in contrast, is seen as difficult as information is sought from unfamiliar and uncertain sources.

3. Information about interchange is critical, and is seen as a key barrier to travel by public transport.

4. Information is required en route especially in the case of disruptions.

5. There are issues with trust over the information provided, especially where information is provided for guidance only.

6. Travellers are concerned with their own journeys so targeting information is essential.

7. Lifestyle changes are opportunities for travel behaviour change.

8. Very often people do not know what they want and must be made aware of information available.

Figure 1. Traveller information and users (adapted from Lyons \& Harman, 2002). 
Pender, Currie, Delbosc and Shiwakoti (2014) show how the combination of smartphone devices and dynamic information (crowdsourced and conventional) can have a positive impact on travellers in the case of disruption in services. The information however must be accurate as issues related to trust could have a negative effect on travellers. Social media can assist in addressing the real time information needs of disrupted commuters and provide operators and governments yet another resource.

Among the benefits that are associated with crowdsourcing, VGI and citizen science, authors have noted that citizen science can be used to provide high quality and effective information for scientific projects with social and environmental benefits through increased awareness and collection of data at the scale and extent that are not possible in regular projects (Bonney et al., 2014). Cooper, Dickinson, Phillips and Bonney (2007) also identified the benefits of increased awareness and ability to monitor local issues, whilst Zook et al. (2010) emphasized the benefits of the speed of response, the ability to tap a range of expertise and the potential and importance of engaging remote participants in an activity.

\section{VGI and New Mobility Services-A Typology}

This article attempts to develop a typology of some of the new mobility services and VGI efforts available in cities around the world in order to support some of the concepts mentioned in Section 2. The rapid developments in the sector have seen the rise and fall of these services with extreme competition being evident between service providers (for example Uber's clash with Didi Dache in China). Some services have been bought out by competitors (e.g. Sidecar was bought by GM after investing heavily in Lyft) and successful start ups bought by large companies (Waze, who was bought by Google). Table 1 provides for the different typologies based on four main characteristics: scale, ownership, type of information and transport mode.

The list provided in Table 1 is not intended to be exhaustive and the examples are just a snapshot of the variety of services provided around the world. These are also some of the more popular and quoted examples in the literature which not necessarily aimed at discussing sustainable mobility, however claiming a contribution to resolving some of the more pressing challenges in transport and indirectly resolving problems of private car use, congestion, pollution and mobility in cities. A quick search by city would uncover a good number of other services, some of which only available in the local language. This has been a major constraint for the research when the website or app, or the information about the service, is not available in the english language.

This list shows the variety of services offered from taxi hailing services which are now available in any city. And even in this category there are the traditional licensed black cabs (Gett) alongside AddisonLee which offer minicab services in the UK. The word disruption has been associated with services like Uber, Didi Dache, Ola and Lyft which match drivers with passengers through an online app and offer ride sharing services. This however has been heavily criticised with Christensen, Raynor and McDonald (2015) demonstrating why Uber is not a disruptive innovation at all, merely disrupting the traditional taxi industry (McGregor, Brown, \& Gloss, 2105).

There is also a unique contribution of VGI in some of these services. Many depend on crowdsourced data (primarily through smartphone technologies) to locate clients. A look at the apps around shared services developed over more recent years show the use of crowdsourced data in the establishment of demand. Bridj uses a team of data scientists considering everything from census data to social-media posts and volunteered location information by users to figure out where a city has the biggest need for bus services. The app then optimizes pickups, drop offs and routing based on demand (Bouton et al., 2015). And whilst more traditional, mode specific apps use conventional data to support travel by public transport (Moovit), there are more apps based on VGI providing services to travellers by car, such as Waze, Google Maps, Apple Maps, and MapQuest which use OpenStreetMap data to optimize data from crowdsourcing. In these cases we find reference to both active and passive crowdsourcing. This affects not only the type and quantity of information but also to a certain extent, quality (Haklay, 2013).

Other examples include the many transport portals which provide multi-modal transport information services in every city and country (TFL Journey Planner and the UbiGo pilot) and those newer services which aim at integrating transport information for use by operators, governments and travellers alike, such as the Traffic Lab in Helsinki which is funded by the Ministry of Transport and Communication. Street Bump on the other hand seems to be the only crowdsourced information portal which is supported by public funds (Boston's Mayor's Office) and freely available to the community at large, as well as use by the municipality to ensure data coverage (Harford, 2014). In addition to that, FixMyStreet works through a charity providing a similar service in the UK, acting as the intermediary between citizens and their local council, although a version that is run by the local council is also available.

The efforts are primarily driven by private enterprise and show how information, both crowdsourced and conventional encourage new services, some of which in support of sustainable mobility principles. It is clear however from the list that there is still very little public sector engagement, something noted by Nash (2010) when referring to Web 2.0 applications.

\section{New Technologies and Services for Sustainable Mobility}

Whilst much of the research into these new mobility services has looked at user profiles (Hinkeldein, Schoen- 
Table 1. A typology of mobility services.

\begin{tabular}{|c|c|c|c|c|c|c|c|c|}
\hline \multirow[t]{2}{*}{ Service } & \multicolumn{2}{|l|}{ Scale } & \multicolumn{2}{|c|}{ Ownership } & \multicolumn{2}{|c|}{ Type of Information } & \multicolumn{2}{|c|}{ Mode of Transport } \\
\hline & Global & $\begin{array}{l}\text { Local } \\
\text { (national) }\end{array}$ & $\begin{array}{l}\text { Public } \\
\text { Owned }\end{array}$ & $\begin{array}{l}\text { Private } \\
\text { Owned }\end{array}$ & Conventional & $\begin{array}{l}\text { Crowd } \\
\text { sourced } \\
\text { or VGI }\end{array}$ & Personal & Shared \\
\hline \multicolumn{9}{|c|}{ Taxi Hailing / Booking Services } \\
\hline Gett & $x$ & & & $x$ & $x$ & & $x$ & \\
\hline Easy Taxi & $x$ & & & $x$ & $x$ & & $x$ & \\
\hline AddisonLee & & $x$ & & $x$ & $x$ & & $x$ & \\
\hline ecabs & & $x$ & & $x$ & $x$ & & $x$ & \\
\hline \multicolumn{9}{|c|}{ Ridesharing Services } \\
\hline Uber & $x$ & & & $x$ & & $x$ & $x$ & \\
\hline Didi Dache & & $x$ & & $x$ & $x$ & & $x$ & \\
\hline Ola & & $x$ & & $x$ & & $x$ & $x$ & \\
\hline Lyft & & $x$ & & $x$ & & $x$ & $x$ & \\
\hline Blablacar & $x$ & & & $x$ & & $x$ & $x$ & \\
\hline
\end{tabular}

Peer-to-Peer Car Renting

Getaround

$\mathrm{X}$

$\mathrm{X}$

$\mathrm{X}$

On Demand Shared Transport Services

UberPool

$\mathrm{X}$

Lyft Line

Kutsuplus

Via

Chariot

Bridj

\section{$x$}

$$
\begin{aligned}
& x \\
& x
\end{aligned}
$$$$
x
$$$$
x
$$

\begin{tabular}{|c|c|c|c|}
\hline Moovit & $x$ & & $x$ \\
\hline Traveline & $x$ & & $x$ \\
\hline DB Bahn & $x$ & $x$ & \\
\hline ratp.fr & $x$ & $x$ & \\
\hline
\end{tabular}

Public Transport Information Services

\begin{tabular}{|c|c|c|c|c|c|c|c|c|}
\hline \multicolumn{9}{|c|}{ Public Transport Information Services } \\
\hline Moovit & & $x$ & & $x$ & $x$ & & & $x$ \\
\hline \multirow{3}{*}{$\begin{array}{l}\text { Traveline } \\
\text { DB Bahn } \\
\text { ratp.fr }\end{array}$} & & $x$ & & $x$ & $x$ & & & $x$ \\
\hline & & $x$ & $x$ & & $x$ & & & $x$ \\
\hline & & $x$ & $\mathrm{x}$ & & $x$ & & & $x$ \\
\hline \multicolumn{9}{|c|}{ Traffic Information Services } \\
\hline Waze & $x$ & & & $x$ & & $x$ & $x$ & \\
\hline Google Maps & $x$ & & & $x$ & $x$ & $x$ & $x$ & \\
\hline Apple Maps & $x$ & & & $x$ & $x$ & $x$ & $x$ & \\
\hline mapquest & $x$ & & & $x$ & $x$ & $x$ & $x$ & \\
\hline TomTom & $x$ & & & $x$ & & $x$ & $x$ & \\
\hline Garmin & $x$ & & & $x$ & & & $x$ & \\
\hline
\end{tabular}

\section{Multi-Modal Travel Information}

Google Transit $\quad x$

UbiGO

Trafiken.nu

TFL Journey Planner

$\mathrm{x}$

$\begin{array}{lll} & & x \\ x & x & x \\ x & x & \\ & x & \\ \end{array}$

$\begin{array}{ll}x & x \\ x & x \\ x & x \\ x & x \\ & x\end{array}$

\section{Traffic Data Repositories}

LIVE Singapore

Traffic Lab Helsinki

$\begin{array}{lllll}x & x & x & x & x \\ x & x & x & x & x\end{array}$

Transport Wiki and Citizen Platforms

Streets Wiki

cyclopath

Street Bump

\begin{tabular}{|c|c|c|c|}
\hline & $x$ & & $x$ \\
\hline \multirow{3}{*}{$x$} & $x$ & & $x$ \\
\hline & & $x$ & $x$ \\
\hline & $x$ & & $x$ \\
\hline
\end{tabular}

FixMyStreet

\begin{tabular}{l}
$x$ \\
$x$ \\
$x$ \\
\hline
\end{tabular}

$\begin{array}{lll} & x & x \\ x & x & x \\ & x & x \\ x & x & x \\ x & x & x \\ & & x\end{array}$


duwe, Graff, \& Hoffmann, 2015), performance (Shaheen \& Cohen, 2007) and challenges (Sochor, Stromberg, \& Karlsson, 2015), not many have reviewed their potential towards sustainable mobility, quantifying the real value of the sharing economy and the value of the information they hold or provide. Martin and Shaheen (2011) have looked at greenhouse gas emission impacts of car sharing and earlier Martin, Shaheen and Lidicker (2010) analysed the impact of car sharing on household vehicle holdings. Even fewer have looked at the implication of using crowdsourced data (VGI) in these services and the impacts on mobility (Gal-Tzur et al., 2014).

Ultimately this has an impact on the level of intervention by governments in support of such services, as well as the likely efforts by governments to promote or otherwise such initiatives. This however will be further discussed in Section 5. Some of the literature in Section 2 has already demonstrated the applications of conventional data and VGI to encourage the use of sustainable transport alternatives. Various applications (listed in Table 1) showed indirect implications on sustainable mobility through the potential of travel behaviour change, use of public transport and shared modes and traffic information. This section describes briefly the technological developments and the implications on behaviour change as a means of achieving sustainable mobility, and the more recent opportunity in applying Responsible Research and Innovation in the field of sustainable mobility.

\subsection{Technology Developments}

According to Castells et al. (2006) mobile devices resulted from the desire for more personal freedom, productivity and efficiency. Mobile technology has allowed for people to choose where they want to be without the constraints of a physical location. Apart from the many additional services offered through smartphone technologies such as maps, real time information and services, the technology has provided for travel which can be easier and more productive. This is also an opportunity for research as few authors have worked on revising the concepts and theories surrounding the value of travel time savings from use of mobile technology (Holley, Jain, \& Lyons, 2008; Mackie et al., 2003; Victoria Transport Policy Institute, 2013), which in turn would have implications on the cost-benefit of greener (public) transport infrastructures which contribute to sustainable mobility goals (Næss, 2016).

In 2008 studies started looking at using mobile phones to determine road and traffic condition and later, transport modes. These devices equipped with an array of sensors and data capture equipment were also able to locate people and their information (Mohan, Padmanabhan, \& Ramjee, 2008; Reddy et al., 2010; Williams, Thomas, Dunbar, Eagle, \& Dobra, 2015; Yuan, Raubal, \& Liu 2012). Since then much of the technology in terms of smartphone technology such as WiFI, Bluetooth, camera, GPS receiver, accelerometers, digital compass and microphone all able to collect information on the go has not only increased rapidly but also become cheaper and more pervasive amongst the population (Haklay, 2013).

The ability of people to collect information from a basic smartphone, through a downloadable app, sensor or through citizen science efforts has evolved very fast. Literature identified in Section 2 (e.g. Weiser et al., 2016) and some of the more open platforms and applications identified in Table 1 (e.g. FixMyStreet, Bridj and Waze) show how public engagement through either explicit or implicit applications or through citizen science projects are leading the way towards a change in the information available. Critics of volunteered information still cast doubts over the quality of the information collected by active and passive means (Flanagin \& Metzger, 2008). Later research however found voluntary data to be as accurate as professional data (Haklay, 2010).

The successful use of technology, whether directly or indirectly through the use of VGI and other conventional data, can have significant implications for sustainable mobility. Research has for at least the last two decades looked at means of collecting data and providing it to users to enhance user experience, improve service delivery and more recently to try and change travel behaviour. These have increased the attractiveness of more traditional services but also allowed for the development of new services, as demonstrated in Section 2 and 3 of this article. Quantifying the impact on sustainable mobility goals requires interdisciplinary research bringing together technologists, transport planners and geographers.

\subsection{Behaviour Change}

In addition to the technological developments a broad array of new work-life arrangements are being put into practice. A number of authors identified the relationship between technology and travel (de Graaff \& Rietveld, 2007; Kwan, 2007). Salmon (1986) categorised the effects into two, namely substitution and complementarity. Technology affects people's use of time and increases the spatial and temporal flexibility of their daily activities (Kwan, 2002). Black (2001) showed how people increased their geographical mobility with the use of mobile communication, which in turn has an impact on travel behaviour (Black, 2001). More research went into the impact of e-commuters with Roy, Martinez, Miscione, Zuidgeest, and van Maarseveen (2012) providing a comprehensive review of impacts on travel distance and number of trips generated. Interestingly Van de Coevering and Schwanen (2006) observed an increase in trip generation when the availability of information about activities and people of interest made people travel more to participate in those activities and meet people.

According to Dal Fiore et al. (2014) these transformations are backed by employers who are allowing employees to telecommute, equipping them with laptops, tablets, smartphones and WiFi connectivity so that their attachment to work and information is not linked to a fixed location. The nomads referred to in The Economist 
in 2008 have now spread to many of society's various layers and the behaviour change towards more complex travel patterns is evident. This makes measuring the behaviour more difficult for transport planners and subsequently for sustainability policy which is being threatened by unsustainable growth in private travel and unrestrained mobility.

The applications which today affect everyday life are collecting information about users, directly or indirectly through the provision of information or through their use. The potential of this big data generated by private and public entities offers an opportunity to design the policy of the future, taking into account the issues associated with the data, the users (sample bias) and the spatio-temporal dimensions to which the data is attached. Research has started in this field with some interesting results leading to new breakthroughs for transport planning (Iqbal, Choudhury, Wang, \& Gonzalez, 2014) and transport behaviour research. Yuan et al. (2012) and Williams et al. (2015) looked at the potential of mobile phone usage records and how it correlates with travel behavior, and mobile phone use as a measure for human mobility. Both studies identify valuable new insights into travel behavior and the challenges posed by the current technologies in fully utilizing the data generated from these technologies. Technologies that help us understand and influence behavior provide us with an opportunity to achieve sustainable mobility goals. Initial research in this area is promising (see for example Hamari, Koivisto, \& Pakkanen, 2014).

\subsection{Applying Responsible Research and Innovation for Sustainable Mobility}

In the European Commission Horizon 2020 Programme there is an emphasis on science with and for society through the application of Responsible Research and Innovation (RRI). RRI is defined as an approach that anticipates and assesses potential implications and societal expectations with regard to research and innovation, with the aim to foster the design of inclusive and sustainable research and innovation. This strongly impinges on the need for public engagement where the future is cocreated with citizens so as to bring on board the widest possible diversity of actors that would not normally interact with each other (European Commission, 2016).

In this context the idea of involving or extending crowdsourcing to real life problems and challenges such as those faced by cities in dealing with transport networks and services is very useful. The potential of using the benefits of VGI to give back citizens a sustainable future is waiting to happen.

\section{Government Role and Responsibilities}

So far this paper has discussed how new mobile technologies have facilitated not only the collection of VGI across a number of sectors but has also presented opportunities for the transport sector to develop new services through which mobility is provided in numerous new ways and has the potential (as some studies have already demonstrated) to contribute to sustainability. There is still however a lot of research which is required to ascertain the overall contribution of these technologies to sustainable mobility. Against this setting, the study aims to also develop insights into the role of governments to use voluntary (crowdsourced) geographic information and social media effectively for sharing information, creating opportunities for collaboration, enhancing government responsiveness, planning and governance to achieve sustainable mobility and climate change goals. The role of governments in this study is emphasized because of the overarching reach and opportunity these technologies have to support the potential of new mobility services through VGI.

Over the years the traditional interactions between Governments and the public have been dramatically challenged by new technologies that have unlocked unimagined opportunities for citizens to do more for themselves and be actively involved in tackling social problems (Bertot, Jaeger, Munson, \& Glaisyer, 2010; Johnston \& Hansen, 2011). Social media, mobile connectivity and the web interactivity have facilitated co-production of knowledge of services traditionally associated with things like neighbourhood watch and school crossing. This has changed the landscape from a dissemination one to a production and collaboration one (Benkler, 2006). Examples include Singapore's Government with You e-government strategy and UK's Big Society programme, both aiming to devolve power and facilitate collaboration between the people and governments.

In his work Linders (2012) identified three models of collaboration and mutual value creation as (i) citizen sourcings (citizen reporting websites); (ii) government as a platform for citizens to propose and make improvements; and (iii) Do-It-Yourself (DIY) government where citizens self-organise and government plays a passive role as a facilitating framework. In this context it is evident to see how the various new mobility services have been facilitated by technology but also by governments. The question however is more related to the third point made by Linders in that to what extent is the facilitating role of governments going to encourage services which have a significant impact on sustainable mobility and what other roles and responsibilities will governments have to or should undertake in order to exploit the full potential of such technologies, crowdsourcing and maybe co-production?

In the context of transport futures governments have certainly a role and a responsibility given the importance of mobility to economic development, well-being, equity and its impact on the environment. Linders (2012) identified five new roles and responsibilities for government and Table 2 attempts to relate them to the transport sector and identify potential benefits and contributions to sustainable mobility. 
Table 2. Government roles and responsibilities and transport sector benefits.

\begin{tabular}{ll}
\hline Role and Responsibility & $\begin{array}{l}\text { Transport Sector Example } \\
\text { (refer to Table 1) }\end{array}$ \\
\hline $\begin{array}{l}\text { The government sets the tone and } \\
\text { defines how actions should be }\end{array}$ & $\begin{array}{l}\text { Facilitating conditions for transport } \\
\text { conducted by setting rules, }\end{array}$ \\
monitoring performance and & seen in the different approaches \\
enforcing compliance. & taken by the US and Europe towards \\
& services like Uber. Rules and \\
& regulations should provide for a level \\
& playing field without restricting ideas \\
& stemming from new technologies and \\
crowdsourced information.
\end{tabular}

Government sponsorship in terms of financial resources or simply administrative/integrative support to co-production efforts.

\section{Bridj (smart urban logistics platform,} which uses big data, mobile technology, and pattern learning to provide a shuttle network that responds to the city's demand patterns) has recently launched a new service under public-private partnership with Kansas City Area Transportation Authority (Business Wire, 2016).
The role of government as mobilizer and motivator to get citizens together and organised.

\section{TrafficLab is lead by the Ministry for} Transport and Communication in Finland and aims to motivate, through access to information, potential new mobility services. Access to mobile technology data and adoption of VGI motivates many of the technologies reviewed in Table 1 and discussed in Section 4.1.
Government has the ultimate responsibility for public well-being by monitoring society-led co-production.

The concerns over passenger safety and security in ride sharing. See the cases of assault linked to Uber (Annear \& Pattari, 2015). The redirection of traffic through residential roads by Waze and creating Waze Traffic in roads not designed for heavy traffic (Bliss, 2015).

The role of government to step in when third parties fail or to set boundaries for government action.

\section{Most transport services are market} led, so-called innovations and disruptors (e.g. Waze, Uber, Lyft) but others are also social enterprises (e.g. FixMyStreet) which contribute to government's' role to maintain infrastructure.
Benefits and Contributions to Sustainable Mobility

As the regulatory framework in the transport sector becomes more liberal, governments have the responsibility to ensure proper understanding of the social and environmental implications of innovations. Only in this manner can new ideas and services truly benefit and contribute to sustainability in transport.

Behaviour change (Section 4.2) is probably the most significant benefit from these new technologies whereby people shift from private cars to shared public transport systems. In this manner there is far more effective use of public infrastructure and reduced emissions.
The benefits of some of the new mobility services have been quantified. Any motivation from government to co-develop or support better services (through the use of conventional and crowdsourced data) could potentially increase benefits.

This is a particularly important role for government as some mobility services have shown not to contribute to sustainability. The adoption of RRI (Section 4.3) could be a potential avenue for developments in VGI and transport research.
Potential of market led innovations, and more importantly social enterprises that have shown significant contribution to the effective functioning of governments (through information sourcing) and promotion of sustainability should be supported by governments.

\subsection{Role and Need for Regulation}

Transport as a sector is heavily controlled by politics and regulation. An underlying principle is driven by the need to support a public infrastructure which drives economies and promote social welfare through the strong relationship that exists between mobility, economy and equity (social well-being). This is mirrored in the long-term vision of Europe's Common Transport Policy and in specific sectors such as EC Regulation 1370/2007 
for the use of competitive tendering in the provision of public transport services (European Commission, 2007) which recognizes the importance of subsidies where services are considered to be part of the welfare state.

It is evident from the review of roles and responsibilities that regulation has a major contribution to make to ensure that new mobility services offer benefits for sustainable mobility. Some of the examples shown in Table 2 raise concerns over the underlying principle driving some of these new services, and cyber libertarian approaches in this sector have stirred many debates over employment, security, safety, violation of contracts and equity amongst scholars (see Epstein, 2015). This increases the responsibilities for governments to search for a balance between true innovation which will contribute to solving some of the more critical concerns affecting our transport systems and societal concerns with growth and sustainable economic growth.

Under the right conditions that facilitate collaboration between governments and the public, and through an understanding of the capabilities embedded in crowdsourced geographic information and citizen engagement, governments and policy makers can start benefitting from the increasingly pervasive stream of information being generated through smartphone technologies, sensors and citizens open to contribute and engage. Open communication channels, public sector champions and change leaders, improved response time for technical problems, effective feedback and timely policy are amongst the conditions which would greatly impact the collaboration between governments and the public. Haklay et al. (2014) identified a list of factors that influence the use of VGI and issues surrounding the adoption of VGI in government. In addition to this, effective regulation which facilitates the availability and use of crowdsourced geographic information could significantly improve policy making and reduce the onus on governments to spend substantial amounts of money on traditional data collection methods which are slowly becoming more redundant and do not reflect the dynamic nature of mobility today.

\section{Conclusions and Further Research}

Continued advancements in technologies, connectivity and user engagement have revolutionised many important sectors and there is no reason to believe that this will not happen in transport. Early innovators are already paving the way to show how new mobility services can help with the transport problems facing our cities. This however has not happened with discussions relating to the information they provide and use, the legal issues, their sustainability and their overall contribution to goals such as air quality improvements and social well-being.

The increase in number and the dynamic nature of these new technologies, data and services also suggest that more research is required to understand their (economic) sustainability, their contribution of sustainabil- ity goals and their impact on cities, where most technologies are deployed. Research into the conceptual requirements and design, system component and evaluation of new services and applications aimed at changing behaviour have already been identified by Weiser et al. (2016) and impinge heavily on their success or otherwise to attract users. And whilst some applications have managed successfully to engage a relatively large user base, research should also be encouraged into ways to promote green alternative transport. For example, can applications like Waze provide green alternative routes and services to its users?

Furthermore research must also be carried out to identify the natural and social factors affecting patterns of mobility and technology use. To date much of the research looking at determinants of travel has not combined the implications of technology use and information provision and collection. Applications such as UbiGreen, Waze, Moovit and others which rely on both collection of VGI and provision of information (feedback to user) can have significant impact on travel behaviour, and subsequently on transport systems sustainability.

The rising trends in crowdsourcing, citizen science and information on the go are providing a new opportunity for innovators, however there is also a role for governments. This role cannot be restricted to regulation and control or to simply ensure the delivery of equitable and sustainable services, but it must also make effective use of the potential embedded in conventional and volunteered geographic information for policy and citizen engagement. Preliminary research into the use of VGI in governments has shown a fair amount of success. More research is therefore required into technology and policy transfer, and the quantification of benefits for governments to invest more in VGI for sustainable mobility.

This paper aimed at a review of the technologies that have developed over the last few years through conventional and crowdsourced (VGI) data, it shed some light on the potential for these new mobility services to achieve sustainable mobility goals and the important role that government has in the use of user generated information and the regulation of new mobility services.

\section{Acknowledgments}

This article is based upon work from COST Action IC1203 ENERGIC (www.vgibox.eu), supported by COST (European Cooperation in Science and Technology).

\section{Conflict of Interest}

The authors declare no conflict of interests.

\section{References}

Adams, J. (2001). The social consequences of hypermobility. RSA Lecture. Retrieved from http://johnadams.co.uk/wp-content/uploads/2006/hypermobi 
lityforRSA.pdf

Annear, S., \& Pattani, A. (2014, February 9). Uber driver charged with assault. Boston Globe. Retrieved from http://www.bostonglobe.com/metro/2015/02/09/ boston-uber-driver-charged-with-indecent-assaultand-battery-boston-police-say/k9eKsX2q95hA9bdM 13lorJ/story.html

Attard, M. (2006). Coping with change. The problems of adopting sustainable transport policies in the small island state of Malta (Ph.D. thesis). University College London, London.

Banister, D. (2007). The sustainable mobility paradigm. Transport Policy, 15(2), 73-80.

Batty, M., Axhausen, K., Fosca, G., Pozdnoukhov, A., Bazzani, A., Wachowicz, . . Portugali, Y. (2012). Smart cities of the future (Paper 188). London: UCL Centre for Advanced Spatial Analysis Working Paper Series.

Benkler, Y. (2006). The wealth of networks: How social production transforms markets and freedom. Yale University Press.

Bertot, J., Jaeger, P., Munson, S. \& Glaisyer, T. (2010). Engaging the public in open government: Social media technology and policy for government transparency. Computer, 43(11), 53-59.

Bertot, J. C., Jaeger, P. T. \& Hansen, D. (2012). The impact of policies on government social media usage: Issues, challenges and recommendations. Government Information Quarterly, 29(1), 30-40.

Black, W. R. (2001). An unpopular essay on transportation. Journal of Transport Geography, 9(1), 1-11.

Bliss, L. (2015, April 29). L.A.'s love/hate relationship with waze continues. One council member is pushing the city to partner with the app to reduce congestion on residential streets. The Atlantic CityLab. Retrieved from http://www.citylab.com/commute/2015/04/las -lovehate-relationship-with-waze-continues/391832

Bonney, R., Shirk, J. L., Phillips, T. B., Wiggins, A., Ballard, H. L., Miller-Rushing, A. J. \& Parrish, J. K. (2014). Next steps for citizen science. Science, 343, 1436-1437.

Bouton, S., Knupfer, S. M., Mihov, I. \& Swartz, S. (2015). Urban mobility at a tipping point. McKinsey \& Company. Retrieved from http://www.mckinsey.com/busi ness-functions/sustainability-and-resource-producti vity/our-insights/urban-mobility-at-a-tipping-point\#0.

Brescia Mobilita. (2014, November 7) \#SocialBus. Brescia Mobilita. Retrieved from http://bresciamobilita.it/ public/resources/brescia\%20mobilita/utenti/eventi/ comunicato-per-la-stampa7nov14.pdf

Business Wire. (2016, February 11). Bridj, Kansas City area transportation authority launch pilot program to extend urban mobility with Ford Transit vans. Business Wire. Retrieved from http://www.kxxv.com/ story/31194041/bridj-kansas-city-area-transportati on-authority-launch-pilot-program-to-extend-urbanmobility-with-ford-transit-vans

Castells, M., Fernández-Ardèvol, M., Qiu, J. L., \& Sey, A. (2006). Mobile Communication and Society. A Global Perspective. Cambridge: MIT Press.
Christensen, C. M., Raynor, M. E., \& McDonald, R. (2015). What is disruptive innovation? Harvard Business Review, December, 44-53.

Christidis, P., \& Ibanez Rivas, J. N. (2012). Measuring road congestion. Institute for Prospective Technological Studies (IPTS), European Commission Joint Research Centre. Retrieved from http://ipts.jrc.ec.euro pa.eu/publications/pub.cfm?id=5600

Cooper, C. B., Dickinson, J., Phillips, T., \& Bonney, R. (2007). Citizen science as a tool for conservation in residential ecosystems. Ecology and Society, 12(2), 11.

Dal Fiore, F., Mokhtarian, P. L., Salomon, I., \& Singer, M. E. (2014) "Nomads at last"? A set of perspectives on how mobile technology may affect travel. Journal of Transport Geography, 41, 97-106.

de Graaff, T., \& Rietveld, P. (2007). Substitution between working at home and out-of-home: The role of ICT and commuting costs. Transportation Research Part A: Policy and Practice, 41(2), 142-160.

Epstein, R. (2015). The libertarian: "Uber and innovation". Hoover institution. Retrieved from http:// www.hoover.org/research/libertarian-uber-and-inno vation.

European Commission. (2004). Towards a thematic strategy on the urban environment. Communication from the Commission to the Council, the European Parliament, the European Economic and Social Committee and the Committee of Regions COM (2004)60 final. European Commission. Retrieved from http://www.europarl.europa.eu/meetdocs/commit tees/rett/20040316/com_com(2004)0060en.pdf

European Commission. (2007). Regulation (EC) No. 1370/2007 of the European Parliament and of the Council of 23rd October 2009 on Public Passenger Transport Services by Rail and by Road. European Commission. Retrieved from http://eur-lex.europa. eu/LexUriServ/LexUriServ.do?uri=OJ:L:2007:315:000 1:0013:EN:PDF

European Commission. (2016). Horizon 2020 Responsible Research and Innovation. European Commission. Retrieved from https://ec.europa.eu/programmes/hori zon2020/en/h2020-section/responsible-research-in novation

European Environment Agency. (2015). Air quality in Europe: 2015 report (EEA Report 5/2015). Retrieved from http://www.eea.europa.eu/publications/airquality-in-europe-2015

Fagnant, D. J., \& Kockelman, K. (2015). Preparing a nation for autonomous vehicles: opportunities, barriers and policy recommendations. Transportation Research A: Policy and Practice, 77, 167-181.

Flanagin, A. J., \& Metzger, M. J. (2008). The credibility of volunteered geographic information. GeoJournal, 72(3-4), 137-148.

Froehlich, J., Dillahunt, T., Klasnja, P., Mankoff, J., Consolvo, S., Harrison, B., \& Landay, J. (2009). UbiGreen: Investigating a mobile tool for tracking and support- 
ing green transportation habits. Proceedings of $\mathrm{CHI}$ 2009. Boston. Retrieved from https://www.cs.wa shington.edu/sites/default/files/hci/papers/tmpGfD Hel.pdf

Gal-Tzur, A., Grant-Muller, S. M., Kuflik, T., Minkov, E., Nocera, S. \& Shoor, I. (2014). The potential of social media in delivering transport policy goals. Transport Policy, 32, 115-123.

Gruppo Brescia Mobilita. (2015) La Mobilita entra in rete. The Gruppo Brescia Mobilita and Social Customer Care. Brescia Mobilita. Retrieved from http://docpla yer.net/988054-The-gruppo-brescia-mobilita-and-so cial-customer-care.html

Haaramo, E. (2014). Death of the car: The tech behind Helsinki's ambitious plan to kill of private vehicles. ZDnet. Retrieved from http://www.zdnet.com/art icle/death-of-the-car-the-tech-behind-helsinkis-ambi tious-plan-to-kill-off-private-vehicles

Haklay, M. (2010). How good is OpenStreetMap information? A comparative study of OpenStreetMap and Ordnance Survey dataset s for London and the rest of England. Environment and Planning B, 37, 682-703.

Haklay, M. (2013). Citizen science and volunteered geographic information: Overview and typology of participation. In D. Sui, S. Elwood, \& M. Goodchild (Eds.), Crowdsourcing geographic knowledge. volunteered geographic information (VGI) in theory and practice (pp. 105-122). Dordrecht: Springer.

Haklay, M., Antoniou, V., Basiouka, S., Soden, R., \& Mooney, P. (2014). Crowdsourced geographic information use in government (Report to GFDRR). London: World Bank.

Hamari, J., Koivisto, J., \& Pakkanen, T. (2014). Do persuasive technologies persuade? A review of empirical studies. In Persuasive Technology (pp. 118-136). Berlin Heidelberg: Springer.

Harford, T. (2014, March 28). Big data: Are we making a big mistake? Financial Times. Retrieved from http:// www.stat.ucla.edu/ yuille/Courses/Stat161-261-Spr ing14/Big\%20data_\%20are\%20we\%20making\%20a \%20big\%20mistake_\%20-\%20FT.pdf

Hinkeldein, D., Schoenduwe, R., Graff, A. \& Hoffmann, C. (2015). Who would use integrated sustainable mobility services-and why? In M. Attard \& Y. Shiftan (Eds.), Sustainable urban transport (Transport and Sustainability, vol. 7, pp. 177-203). London: Emerald Group Publishing Limited.

Holley, D., Jain, J., \& Lyons, G. (2008). Understanding business travel time use and its place in the working day. Time and Society, 17(1), 27-46.

Iqbal, S., Choudhury, C. F., Wang, P., \& Gonzalez, M. C. (2014). Development of origin-destination matrices using mobile phone call data. Transportation Research Part C: Emerging Technologies, 40, 63-74.

Iveroth, E., \& Bengtsson, F. (2014). Changing behavior towards sustainable practices using Information Technology. Journal of Environmental Management, 139, 59-68.
Johnston, E., \& Hansen, D. (2011). Design lessons for smart governance infrastructures. In A. P. Balutis, T. F. Buss, \& D. Ink (Eds.), American governance 3.0: rebooting the public square? (pp. 197-212). New York: Routledge.

Kenyon, S., \& Lyons, G. (2003). The value of integrated multimodal traveller information and its potential contribution to modal change. Transportation Research Part F: Traffic Psychology and Behaviour, 6(1), $1-21$.

Kramers, A. (2014). Designing next generation multimodal traveler information systems to support sustainability-oriented decisions. Environmental Modelling and Software, 56, 83-93.

Kwan, M. P. (2002). Time, information technologies and the geographies of everyday life. Urban Geography, 23, 471-482.

Kwan, M. P. (2007). Mobile communications, social networks, and urban travel: Hypertext as a new metaphor for conceptualising spatial interaction. The Professional Geographer, 59, 434-446.

Lanzendorf, M. (2014). The black spot of policy evaluations: Social change and mobility 2.0. Paper presented at the Royal Geographic Society (with IBG) Annual Meeting, London. Retrieved from http:// conference.rgs.org/AC2014/104

Linders, S. (2012). From e-government to wegovernment: Defining a typology for citizen coproduction in the age of social media. Government Information Quarterly, 29(4), 446-454.

Lyons, G. (2001). Towards integrated traveller information. Transport Reviews, 21, 217-235.

Lyons, G., \& Harman, R. (2002). The UK public transport industry and provision of multi-modal traveller information. International Journal of Transport Management, 1, 1-13.

Mackie, P. J., Wardman, M., Fowkes, A. S., Whelan, G., Nellthorp, J., \& Bates, J. (2003). Values of travel time savings UK. University of Leeds. Retrieved from http://eprints.whiterose.ac.uk/2079/2/Value_of_tra vel_time_savings_in_the_UK_protected.pdf

Manovich, L. (2009). The practice of everyday (media) life: From mass consumption to mass cultural production? Critical Inquiry, 35, 319-331.

Martin, E. W., \& Shaheen, S. (2011). Greenhouse gas emission impacts of carsharing in North America. Intelligent Transportation Systems, IEEE Transactions, 12(4), 1074-1086.

Martin, E. W., Shaheen, S., \& Lidicker, J. (2010). Impact of carsharing on household vehicle holdings: Results from North American shared-use vehicle survey. Transportation Research Record: Journal of the Transportation Research Board, 2143, 150-158.

McGregor, M., Brown, B., \& Gloss, M. (2015). Disrupting the cab: Uber, ridesharing and the taxi industry. The Journal of Peer Production, 6. Retrieved from http:// peerproduction.net/issues/issue-6-disruption-andthe-law/essays/disrupting-the-cab-uber-ridesharing- 
and-the-taxi-industry

Meddin, R., \& DeMaio, P. (2014). The bike-sharing world map. Bike-Sharing World. Retrieved from www.bikesharingworld.com

Metz, D. (2015). Peak car in the big city: Reducing London's transport greenhouse gas emissions. Case Studies in Transport Policy, 3(4), 367-371.

Miller, H. J., (2013). Beyond sharing: Cultivating cooperative transportation systems through geographic information science. Journal of Transport Geography, 31, 296-308.

Mohan, P., Padmanabhan, V., \& Ramjee, R. (2008). Trafficsense: Rich monitoring of road and traffic conditions using mobile smartphones. In Proceedings of the Conference on Embedded Networked Sensor Systems (pp. 323-336). New York: ACM.

Musso, A., \& Corazza, M. V. (2015). The European bus system of the future: Research and innovation. Transportation Research Procedia, 5, 13-29.

Næss, P. (2016). Inaccurate and biased: Cost-benefit analyses of transport infrastructure projects. In P. Næss, L. Price, \& H. Despain (Eds.) Crisis System: A critical realist and environmental critique of economics and the economy. New York: Routledge.

Nash, A. (2010). Web 2.0 applications for improving public participation in transport planning. Proceedings of the Transportation Research Board 89th Annual Meeting (pp. 1-25). Washington DC: Transportation Research Board.

Panagiotopoulos, P., Bigdeli, A. Z., \& Sams, S. (2014). Citizen-government collaboration on social media: The case of Twitter in the 2011 riots in England. Government Information Quarterly, 31, 349-357.

Pender, B., Currie, G., Delbosc, A., \& Shiwakoti, N. (2014). Social media use during unplanned transit network disruptions: A review of literature. Transport Reviews, 34(4), 501-521.

Prelipcean, A., Gidofalvi, G., \& Susilo, Y. O. (2014) Mobility collector. Journal of Location Based Services, 8(4), 229-255.

Reddy, S., Mun, M., Burke, J., Estrin, D., Hansen, M., \& Srivastava, M. (2010). Using mobile phones to determine transportation modes. ACM Transactions on Sensor Networks, 6(2), 13.1-13.27.

Roy, P., Martinez, A. J., Miscione, G., Zuidgeest, M. H. P., \& van Maarseveen, M. F. A. M. (2012). Using social network analysis to profile people based on their ecommunication and travel balance. Journal of Transport Geography, 24, 111-122.
Rushe, D. (2013, June 11). Google buys Waze map app for \$1.3bn. The Guardian. Retrieved from http:// www.theguardian.com/technology/2013/jun/11/goo gle-buys-waze- maps-billion.

Salmon, I. (1986). Telecommunication and travel relationship: a review. Transportation Research Part A: Policy and Practice, 20A, 223-238.

Shaheen, S., \& Cohen, A. (2007). Growth in worldwide carsharing: An international comparison. Transportation Research Record: Journal of the Transportation Research Board, 1992, 81-89.

Sochor, J., Stromberg, H., \& Karlsson, I. C. M. (2015). Implementing mobility as a service. Challenges in integrating use, commercial and social perspectives. Transportation Research Record: Journal of the Transportation Research Board, 2536, 1-9.

Steinbock, D. (2005). The mobile revolution. The making of mobile services worldwide. London: Kogan Page.

The Economist. (2008). Nomads at last. The Economist. Retrieved from http://www.economist.com/node/ 10950394

Van de Coevering, P., \& Schwanen, T. (2006). Reevaluating the impact of urban form on travel patterns in Europe and North-America. Transport Policy, 13, 229-239.

Victoria Transport Policy Institute. (2013). Chapter 5.2 Travel Time. Victoria Transport Policy Institute. Retrieved from www.vtpi.org/tca/tca0502.pdf.

Weiser, P., Scheider, S., Bucher, D., Kiefer, P., \& Raubal, M. (2016). Towards sustainable mobility behavior: Research challenges for location-aware information and communication technology. Geolnformatica, 20, 213-239.

Williams, N. E., Thomas, T. A., Dunbar, M., Eagle, N., \& Dobra, A. (2015). Measures of human mobility using mobile phone records enhanced with GIS data. PLOS ONE, 10(7), 1-16.

Winter, S., Sester, M., Wolfson, O., \& Geers, G. (2011). Towards a computational transportation science. Journal of Spatial Information Science, 2, 119-126.

Yuan, Y., Raubal, M., \& Liu, Y. (2012). Correlating mobile phone usage and travel behavior-a case study of Harbin, China. Computers, Environment and Urban Systems, 36, 118-130,

Zook, M., Graham, M., Shelton, T., \& Gorman, S. (2010). Volunteered geographic information and crowdsourcing disaster relief: A case study of the Haitian earthquake. World Medical and Health Policy, 2(2), 7-33.

\section{About the Authors}

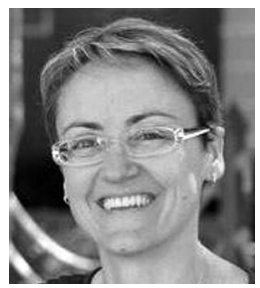

Maria Attard is Associate Professor of Geography and the Director of the Institute for Climate Change and Sustainable Development at the University of Malta. She specializes in urban transport, Geographic Information and policy. Between 2002-2009 she served as a consultant to Government on transport strategy and policy. She studied at the University of Malta and completed her PhD in 2006 at UCL (London). She is currently involved in NECTAR and WCTRS. 


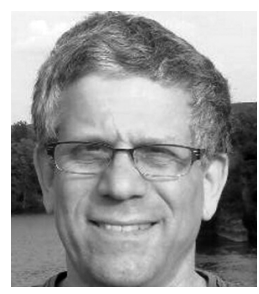

Muki Haklay is a Professor of Geographical Information Science at UCL. He is the co-director of ExCiteS and works on a range of research projects that involve participatory mapping and science methods. His research interests include public access to environmental information and the way in which the information is used by a wide range of stakeholders, citizen science and in particular applications that involve community-led investigation, development and use of participatory GIS and mapping, and Human-Computer Interaction ( $\mathrm{HCl}$ ) for geospatial technologies.

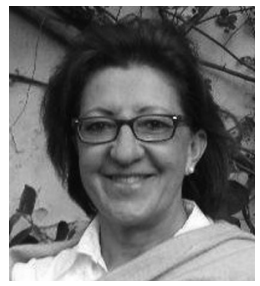

Cristina Capineri is Associate Professor of Geography at the Department of Social, Political and Cognitive Studies (DISPOC), University of Siena, Italy. Her research interests concern broadly transport and telecommunication networks, GI Science and Volunteered Geographic Information, local development and sustainable development, environmental indicators, organic agriculture and landscape. 